\title{
CONTRIBUTION OF 18F-FDG PET/CT IN OCCULT BREAST CARCINOMA
}

\author{
APORTACIÓN DE LA 18F-FDG PET/TC EN TUMORES OCULTOS DE MAMA
}

\author{
Valhondo-Rama, Raquel'; Brenes Sánchez, Juana M², Wakfie-Corieh, Cristina G'; Rodríguez Rey, Cristina'; Herrera De \\ la Muela, María ${ }^{2}$; Carreras Delgado, José $L^{1}$ \\ ${ }^{1}$ Department of Nuclear Medicine, Hospital Clínico San Carlos, Madrid. \\ 2 Department of Obstetric and Gynaecology, Hospital Clínico San Carlos, Madrid.
}

Keywords:
Axillary
adenopathies;
Breast Carcinoma;
Positron Emission
Tomography;
Staging.
Palabras clave:
Adenopatías axilares;
Carcinoma de mama;
Tomografía
de emisión de
positrones;
Estadificación.

Keywords:

adenopathies;

Breast Carcinoma

Tomography;

Adenopatías axilares;

Tomografía

positrones;

Estadificación.

\begin{abstract}
Early detection of primary lesion with isolated axillary lymph node metastasis without any clinical or radiological evidence of tumour is still a pending issue. It is important to offer these patients a better management and survival. The definition of occult breast carcinoma is redefined as radiological diagnostic techniques progress.

We emphasize the contribution of whole-body fluorine-18 fluorodeoxyglucose positron emission tomography associated with computed tomography for staging, surgical approach and adjuvant treatments recommendations for these patients.
\end{abstract}

\begin{abstract}
Resumen
La detección precoz de la lesión primaria en casos de metástasis aisladas de ganglios linfáticos axilares, sin evidencia clínica ni radiológica de tumor, sigue siendo una cuestión pendiente de resolver. Sin embargo, es importante para ofrecer a estos pacientes un mejor manejo y mayor supervivencia. La definición de carcinoma oculto de mama se redefine a medida que avanzan las técnicas radiológicas de imagen diagnóstica.

Con este trabajo queremos resaltar la aportación de la tomografía por emisión de positrones con flúor-18 fluorodeoxiglucosa asociada a tomografía computarizada de cuerpo entero para la estadificación, el abordaje quirúrgico y las recomendaciones de tratamientos adyuvantes en estos pacientes.
\end{abstract}

\section{INTRODUCTION}

Thanks to advances in diagnostic techniques the incidence of occult breast carcinoma (OBC) has significantly decreased, today estimated in $0,3-1 \%$ of breast cancers overall.(1-7) Nowadays, a patient has OBC when presenting metastatic axillary lymphadenopathies without palpable tumour in the ipsilateral breast, a non-diagnostic radiological assessment for breast tumour and no other primary neoplasm detected outside the breast which may potentially affect the axillary lymph nodes. $(4,8)$ The final diagnosis is based on the histopathological findings and the immunohistochemistry.

Lymphoma is the most common malignant cause of axillary lymphadenopathy followed by breast carcinoma. Less common primary tumours which can metastasize to axillary lymph nodes are thyroid, lung, stomach, pancreas, ovary, colon and various sarcomas. $(1,3,5)$
There are also some theories that explain this carcinoma arising from ectopic breast tissue due to a failure of resolution of the embryologic mammary ridge, so it could be classified as primary OBC in axillary lymph nodes instead of metastatic $\mathrm{OBC}$, with different management. $(5,8,9)$

Clinical examination, breast ultrasound (US), mammography (MM), contrast-enhanced CT, magnetic resonance imaging (MRI), fine needle aspiration cytology (FNAC) and biopsy are the most frequently tests used for searching the primary lesion(1-3) but whole-body fluorine-18 fluorodeoxyglucose positron emission tomography associated with computed tomography ( $\mathrm{WB}^{18} \mathrm{~F}$ FDG PET/CT) has its role too.

We describe here how the findings on $\mathrm{WB}^{18} \mathrm{~F}-\mathrm{FDG}$ $\mathrm{PET} / \mathrm{CT}$ represented a change in the staging and/ or in the therapeutic management in two patients with $\mathrm{OBC}$ in our Centre. 


\section{CASES REPORT}

\section{PATIENT 1:}

In January 2013 right axillary adenopathies were detected in a 63-year-old woman by MM, MRI, and US without lesions in mammary parenchyma. FNAC and biopsy confirmed metastases of infiltrating Luminal A lobular carcinoma.

$\mathrm{WB}^{18} \mathrm{~F}-\mathrm{FDG} \mathrm{PET} / \mathrm{CT}$ showed multiple right axillary adenopathies plus a pathological FDG deposit in a subcarinal lymph node (Figure 1), whose FNAC reported metastasis of breast adenocarcinoma, which directly supposes stage IV.

Neoadjuvant hormone therapy was initiated (Letrozole). Neoadjuvant chemotherapy was rejected due to comorbidities. Right axillary lymphadenectomy showed 6 of 15 nodes with macrometastasis. She received 50 Grays (Gy) of adjuvant radiotherapy (RT) on right breast, axilla and supraclavicular region plus mediastinum, and continued with Letrozole.

During follow-up, high CEA value was spotted four years later. Ca 15.3, whole-body bone scintigraphy, colonoscopy and oral panendoscopy were normal. $\mathrm{PET} / \mathrm{CT}$ however reported left pleural implants (Figure 2.A).

Fulvestrant was initiated but CEA level persisted high. New PET/CT study showed enlargement of the pleural implants (Figure 2.B). Chemotherapy was changed to Exemestane-Everolimus. After 16 months of stabilization, $\mathrm{PET} / \mathrm{CT}$ revealed again progression of pleural implants (Figure 2.C). Therapy with Nab-Paclitaxel was agreed but changed into Tamoxifen because of poor tolerance.

Currently, she remains stable with Tamoxifen on follow-up with mammography, tumour markers and WB ${ }^{18}$ F-FDG PET/CT (last follow-up on December 2020) with no lesions identified in breast tissue.
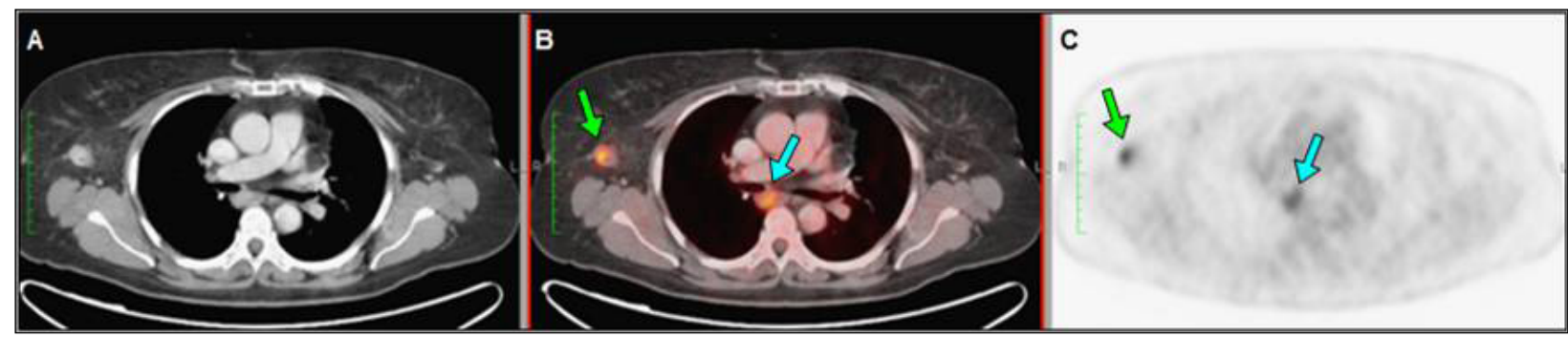

Figure 1. Patient 1. First WB18F-FDG PET/C. Axial planes, (A) CT, (B) PET/CT, (C) PET. Green arrows: the largest axillary adenopathy $(1.8 \mathrm{~cm})$ with maximum standard uptake value on PET $(S U V \max )=5,6$. Blue arrows: subcarinal adenopathy $(1.4 \mathrm{~cm}, S U V m a x 5.1)$.
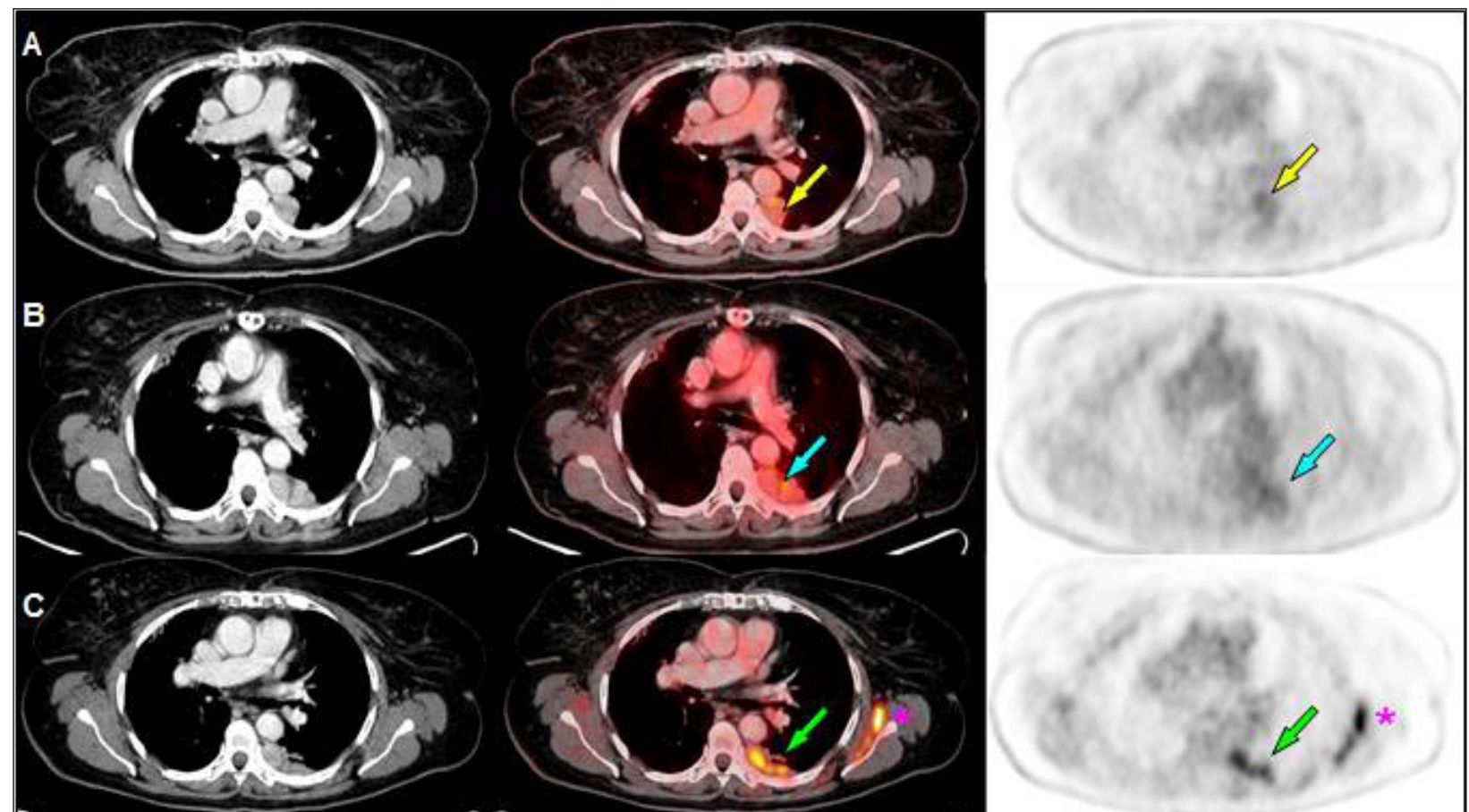

Figure 2. Patient 1. WB18F-FDG PET/CT, axial planes. (A) January 2017: left pleural implants (yellow arrows), with SUVmax 3.4. (B) September 2017: progression of pleural implants (blue arrows). (C) January 2019: progression of pleural implants (green arrows); inflammatory FDG uptake in left shoulder muscles (asterisk). 


\section{PATIENT 2:}

In December 2018, high CEA value was detected during the follow-up of a 73-year-old woman with previous sigma and endometrial adenocarcinoma surgically treated.

Body-CT spotted a pathological adenopathy in right axilla whose biopsy suggested tumour from female genital tract, without ruling out pancreas or gastrointestinal origin. In January 2019, colonoscopy and oral panedoscopy were normal.

WB ${ }^{18}$ F-FDG PET/CT (February 2019) showed multiple right axillary lymphadenopathies and incidental FDG uptake in a hypodense nodule in the left thyroid lobe (Figure 3).

US guided FNAC of the thyroid nodule was compatible with Bethesda 4 follicular neoplasm, pending surgery until treatment of $\mathrm{OBC}$ is completed.

\section{DISCUSSION}

Occult breast carcinoma (OBC) was classified by the American Joint Committee on Cancer (AJCC) as cT0, cN1-2, M0, Stage II-III. However, its prognosis seems better than stage II palpable breast carcinoma. After axillary lymph node metastases, the time of appearance of primary breast cancer varies from 0.5 to 5 years. Early identification of the primary site and its appropriate staging and management result in better prognosis. $(1,6,7)$

MRI has achieved a sensitivity of $89 \%$ with $74 \%$ of specificity $(1,3-5)$. When combining MM, US and MRI the sensitivity goes up to $99.4 \%$.(8) Blood tumour markers have also a role,(3) as showed in our patients.

WB ${ }^{18} \mathrm{~F}-\mathrm{FDG}$ PET/CT has lower spatial resolution than MRI (sensitivity $63 \%$, specificity $91 \%)(1,3,10)$ However, several authors confirm its efficacy to
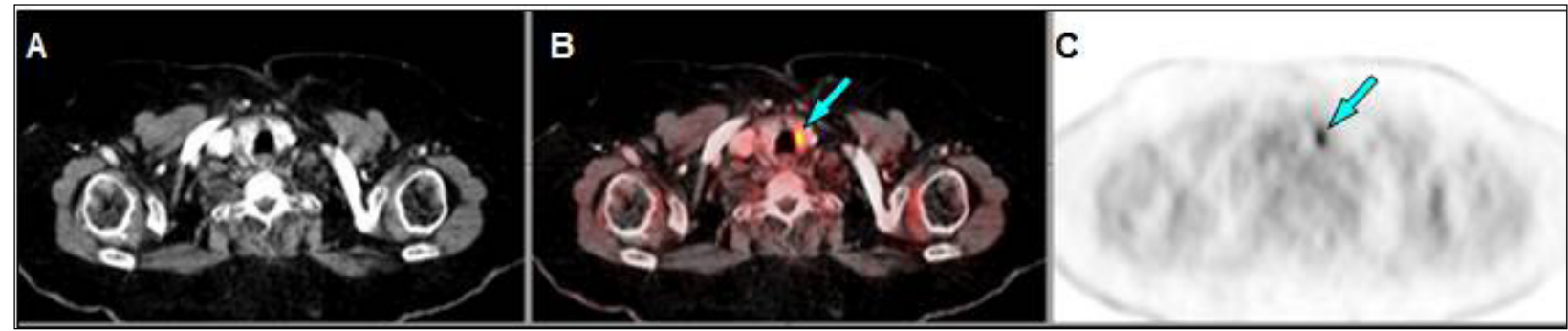

Figure 3. Patient 2. WB18F-FDG PET/CT, axial planes, (A) CT, (B) PET/CT, (C) PET. Focal FDG uptake in an incidental thyroid nodule (blue arrows) sized $1.2 \mathrm{~cm}$, SUVmax 9.3 .

Biopsy of the largest axillary adenopathy reported metastasis of Luminal A breast adenocarcinoma.

With the diagnosis of right OBC, ipsilateral axillary lymphadenectomy was carried out ( 8 of 13 nodes positive). She began adjuvant Letrozole and adjuvant RT (50Gy on right breast, axilla and supraclavicular region). Chemotherapy was dismissed because of multiple comorbidities.

CEA value remains high (13.7 $\mathrm{ng} / \mathrm{mL}$ on December 2020, normal range 0.1-5.0) but last WB ${ }^{18}$ F-FDG PET/CT (January 2021) confirms disease stabilization. Breast tissue persists without lesions. Increased FDG uptake was observed in the thyroid nodule. Surgery has been rejected for the moment by the patient because of COVID-19 pandemic situation. She continues maintenance therapy with Letrozole.

This study involving human beings is in accordance with the ethical standards of institutional and national research committees and with the 1964 Helsinki Declaration and its later amendments or comparable ethical standards. The two patients signed a generic consent for ${ }^{18} \mathrm{~F}-\mathrm{FDG} \mathrm{PET} / \mathrm{CT}$. explore in only one examination several lymph node stations and distant metastasis and to rule out other primary sites.(1-4,9) In our patients, stage IV was early diagnosed in Patient 1 thanks to pathological metabolic activity in a non-enlarged subcarinal lymph node. In Patient 2, the PET/CT study did not change the diagnosis and staging of OBC but another primary neoplasm was early detected. WB ${ }^{18}$ F-FDG PET/CT seems especially useful when dense breasts, multicentric disease and/or breast prostheses.

Regarding the therapeutic approach, the traditional choice was like primary breast cancer with nodal metastases: systemic chemotherapy, mastectomy, and axillary lymph nodes dissection. However, the impact of mastectomy on survival is not clear and histopathological examination of the mastectomy specimen do not reveal the primary tumour in one third of patients. $(1,6-8)$

Current National Comprehensive Cancer Network (NCCN) Guidelines ${ }^{\circledast}$ recommend modified radical mastectomy, with the option of breast preservation plus radiation for $\mathrm{N} 1$ patients. Johnson et al(7) proved that breast preservation plus RT is reasonable regardless of nodal stage, with similar or even better overall survival comparing to mastectomy. Some studies also suggest that only 
breast observation does not adversely influence survival, whereas others report a local recurrence rate of $15.4-63.6 \%$ in those cases.(6-8) Yang et al(10) support that OBC might have an excellent response to neoadjuvant chemotherapy achieving pathological complete response, with better survival for these patients. We consider that further studies are required to approve this option taking into account the psychological impact too.

In conclusion, findings on ${ }^{18} \mathrm{~F}-\mathrm{FDG} \mathrm{PET} / \mathrm{CT}$ can determine a better management. We strongly support its utility for a proper diagnosis, staging and follow-up of patients with OBC. It indeed should be indicated when the primary tumour remains undetected by other diagnostic techniques, specially today when there are new PET/CT equipments available with improved sensitivity and specificity in breast diseases. On the other hand, surgical treatment with breast preservation plus RT instead of mastectomy should be considered in all cases of OBC. Multidisciplinary approach is crucial to reach an optimal management and prognosis for these patients.

\section{FUNDING}

This research did not receive any specific grant from funding agencies in the public, commercial, or not-for-profit sectors.

\section{BIBLIOGRAPHY}

1. Soundararajan R, Naswa N, Karunanithi S, Walia R, Kumar R, Bal C. Occult breast primary malignancy presenting as isolated axillary lymph node metastasis - early detection of primary site by $18 \mathrm{~F}-\mathrm{FDG}$ PET/CT. Nucl Med Rev. 2016;19:B5-7.

2. Liu M, Liu B, Song $\mathrm{Y}$, Ding L, Dong L. FDG PET/CT reveals the primary tumor in a patient with occult breast carcinoma undetected by other modalities. Clin Nucl Med. 2014;39(8):755-757.

3. Takabatake D, Taira N, Aogi K, et al. Two cases of occult breast cancer in which PET$\mathrm{CT}$ was helpful in identifying primary tumors. Breast Cancer. 2008;15(2):181-184.

4. Banzo J, Ubieto MA, González C, et al. Papillary thyroid carcinoma synchronous with breast cancer: An incidental finding in an $18 \mathrm{~F}$ FDG PET-CT study carried out in a search for occult breast cancer. Rev Esp Med Nucl Imag Mol. 2012;31(4):213-215. DOI: 10.1016/j. remnie.2012.06.013

5. Park JS, Lee AY, Bae SG, Lee SM. Hypermetabolic axillary mass on $18 \mathrm{f}$ FDG PET/CT: Breast cancer arising from accessory breast tissue. Nucl Med Mol Imaging. 2010;44(4):300303.

6. Ge LP, Liu XY, Xiao Y, et al. Clinicopatho- logical characteristics and treatment outcomes of occult breast cancer: A SEER population-based study. Cancer Manag Res. 2018;10:4381-4391.

7. Johnson HM, Irish W, Vohra NA, Wong JH. The effect of local therapy on breast cancerspecific mortality of women with occult breast cancer and advanced nodal disease (N2/N3): a population analysis. Breast Cancer Res Treat. 2019;177(1):155-164. DOI: 10.1007/s10549019-05285-x

8. Terada M, Adachi Y, Sawaki M, et al. Occult breast cancer may originate from ectopic breast tissue present in axillary lymph nodes. Breast Cancer Res Treat. 2018;172(1):1-7. DOI: 10.1007/s10549-018-4898-4

9. Uribe A, Berrios C, Yi Li Y. Cáncer en mama axilar: Revisión de la literatura a propósito de un caso. Rev Chil Obstet Ginecol. 2017;82(4):416-423. DOI: 10.4067/s071775262017000400416

10. Yang H, Li L, Zhang M, Zhang S, Xu S, Ma X. Application of neoadjuvant chemotherapy in occult breast cancer: Five case reports. Medicine (Baltimore). 2017;96(40):e8200. DOI: 10.1097/MD.0000000000008200.

\section{CONFLICT OF INTEREST}

The authors declare that they have no conflicts of interest.

Si desea citar nuestro artículo:

Valhondo-Rama R, Brenes Sánchez JM, Wakfie-Corieh CG, Rodríguez Rey C, Herrera De la Muela M, Carreras Delgado JL. Contribution of WholeBody Fluorine-18 Fluorodeoxyglucose Positron Emission Tomography. An RANM. 2021:138(01): 92-95. D0I: 10.32440/ar.2021.138.01.rev10 